\title{
Sobre resenhas científicas
}

\author{
Clovis Ultramari* \\ Manoela Massuchetto Jazar ${ }^{\star \star}$
}

No primeiro volume do periódico The New York Review of Books, hoje referência fundamental no cenário da crítica editorial mundial, os editores Epstein e Silvers lançavam dúvida sobre o interesse do público leitor em resenhas e críticas, a despeito de seguros da importância de tais trabalhos:

The hope of the editors is to suggest, however imperfectly, some of the qualities which a responsible literary journal should have and to discover whether there is, in America, not only the need for such a review but the demand for one (EPSTEIN; SILVERS, 1963).

0 pouco espaço dedicado pela maioria dos periódicos científicos à forma literária da resenha pode, de fato, justificar-se por um possível reduzido interesse do leitor. De imediato, preferimos acreditar que se esse interesse é mesmo pequeno, ele resulta de hábito ainda não descoberto e não provocado. Todavia, o importante é que essa situação revela um baixo volume de debate sobre a nossa própria produção científica. Se essa segunda suposição guarda algo de correto, estaríamos distantes da salutar controvérsia entre pares de uma academia.

Discutimos aqui a pouca expressividade do debate científico em seu formato de publicação; reconhecemos que esse fato compõe um cenário maior, indicando também a falta do diálogo científico oral. Martin (2000, p. 202) sintetiza a ideia de baixa ocorrência do debate e ainda sugere um despropósito no seu formato mais usual:

Scientific debates are an artificial process of acting rather than a spontaneous exchange of ideas. Protagonists carefully rehearse their arguments, often by trying them out on friends or advisers, exploring possible lines of argument and rejecting those that don't work well in public forums. The aim in a debate is to "win," namely to be recognised as having superior arguments, rather than to open a dialogue, explore commonalities or modify one's position.

\footnotetext{
*Pontifícia Universidade Católica do Paraná - PUC-PR, Curitiba-PR, Brasil (ultramari@yahoo.com).

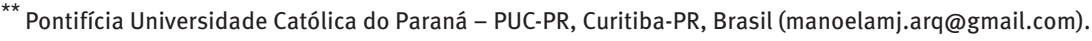


Mesmo com o propósito de tão somente difundir uma obra recém-lançada, a "resenha informativa" não é comum entre nós. Não temos a prática de fazê-la e, na maioria, responde a um pedido específico de um editor. No caso da "resenha crítica", aquela realizada com o intuito de debater o conteúdo e contextualização de uma obra, o cenário é ainda mais preocupante. A reduzida valoração dada à difusão de novas obras é intrigante por, minimamente, não demonstrar interesse no objetivo precípuo de uma obra, que é o de ser lida. Do ponto de vista epistemológico da ciência, é intrigante o baixo número de debate sobre obras publicadas, de discussões sobre suas contextualizações e de demonstração de receptividade a revisões de verdades há muito assumidas. Podemos estar, de fato, substituindo a leitura de livros pela de artigos; entretanto, não parece ser essa a justificativa para o fato que discutimos aqui. Entendemos que há uma dificuldade operacional adicional para editores reservarem espaços para o debate sobre aquilo que se publica ou se pesquisa de forma consistente em cada um dos números dos seus periódicos científicos, seja por meio de resenhas ou de pontos de vista. Entendemos também que há pouco incentivo para que isso ocorra quando da elaboração de índices de ranking e de classificação desses mesmos periódicos. Essas seriam questões operacionais - impostas - menos relevantes do que a inexistência de um ambiente entre os próprios pesquisadores que induza a argumentações ex-post de uma pesquisa ou de uma publicação. Poder-se-ia aqui lembrar da "assimetria epistêmica" que nos faz, naturalmente, pouco interessados na ideia do outro. Poder-se-ia também considerar que a atividade cientifica, conforme lembrado por Bourdieu (1983), faz-se com interesses outros que não apenas aqueles que dela são esperados, como os políticos e os de prestígio social. Há, também, um conforto e uma segurança no não debate. Por último, adentrando no atributo do debate que pouco existe, tem-se a crítica de Milton Santos (1994), ao discutir globalização e pós-modernidade, de que este seria meramente adjetivo e pouco substantivo.

Resenhas científicas são quase tão antigas quanto a própria produção científica. As primeiras resenhas teriam sido formuladas no final do século XVII, constituindo relatos de fatos e produções feitas pela ciência de então. A publicação pioneira que se reconhece desse gênero é o Journal des Sçavans, com primeiro número datado de 1665. Estudar o que a ciência produz, a forma como produz, quem a produz, onde é produzida e suas tendências são questões epistemológicas que não apenas ajudam a apreender o contexto de nossas próprias produções, mas também facilitam, pragmaticamente, a busca de referências contributivas.

A despeito desse valor, em meio a um cenário de grande e diversificada produção científica, a importância dada à publicação de resenhas, críticas, esforços de epistemologia e, sobretudo, análises bibliométricas já foi motivo de críticas, sugerindo a ideia de uma "second-class citizen of scientific literature” (RILEY; SPREITZER, 1970, apud NICOLAISEN, 2005).

Contrariamente, Spink, Robin e Schamber (1998) revalorizam a atividade da crítica e nos lembram que essa pode, ao analisar, interpretar, aceitar ou rejeitar ideias, instaurar um profícuo e necessário fórum de debate até então eventualmente não proporcionado pela obra original. De modo similar, Jones, Fleenor e Summers (2004) afirmam que: 
For applied scientists more generally, being aware of important scholarly and practice trends can prove invaluable, both for addressing problems using commonly understood, legitimized language (e.g. buzzwords) and for generating important new research threads and practices.

De modo geral, e do ponto de vista de quem a escreve, há três formas de se elaborar uma resenha: a primeira, denominada curta, tem a finalidade, tradicionalmente, de subsidiar decisões de compra das bibliotecas e são produzidas de forma contemporânea à obra original; a segunda, a de opinião, com média extensão, usa como mídia jornais e revistas de grande circulação, como, por exemplo, New York Book Review, The Guardian Review, The Times Literary Suplement e, no Brasil, os cadernos Ilustrada, da Folha de S.Paulo, e o Sabático, de $O$ Estado de S.Paulo; e a terceira, de caráter acadêmico, restringe-se a periódicos científicos, em espaços residuais àqueles disponibilizados a artigos. Dessa tipologia, ressalta-se a importância da síntese, da difusão, da seleção de interesses e, mais importante ainda, da provocação de um debate que se inicia não na mera reprodução daquilo que é feito pela ciência, mas, antes, na crítica, positiva ou negativa, do que é produzido.

Zuccala e Van Leeuwen (2011), em seus estudos empíricos nas áreas de história e literatura, igualmente revalorizam o exercício das resenhas e as tipificam em duas formas: aquelas de tipo 1, que referenciam apenas o livro analisado; e as de tipo 2, que servem-se também de outras fontes científicas. Esses mesmos estudos revelam que, enquanto as de tipo 1 são mais comumente publicadas, as de tipo 2 contam com maior potencial analítico.

O levantamento que se apresenta a seguir tem o interesse de investigar o cenário das resenhas e, com isso, fazer uma identificação inicial sobre o debate entre pares na área de Planejamento Urbano Regional / Demografia no Brasil. A título de exemplo, selecionamos periódicos de maior referência científica segundo a Coordenação de Aperfeiçoamento de Pessoal de Nível Superior (Capes), ou seja, os classificados como A1 e A2 pelo Qualis Periódicos desta instituição, especificamente da área de interesse. Por meio da análise dos últimos dez números de cada um dos periódicos selecionados (24 na categoria A1 e 31 na categoria A2), computamos a existência, entre seus artigos, de resenhas ou críticas científicas. Os resultados parciais e totais estão demonstrados na Tabela 1.

TABELA 1

Críticas ou resenhas publicadas nos últimos dez números de periódicos A1 em Planejamento Urbano e Regional / Demografia - 2014

\begin{tabular}{clc}
\hline \multicolumn{1}{c}{ ISSN } & \multicolumn{1}{c}{ Periódicos } & Críticas ou resenhas nos últimos dez números \\
\hline & Periódicos A1 & \\
$1679-9275$ & Acta Scientiarum. Agronomy & 2 \\
$0264-2751$ & Cities & 10 \\
$1535-6841$ & City \& Community & 3 \\
$1435-9871$ & Demographic Research & 2 \\
$1470-160 X$ & Ecological Indicators & 2 \\
$1708-3087$ & Ecology and Society & 5 \\
$0973-0826$ & Energy Sustainable Development & 0 \\
$1866-6280$ & Environmental Earth Sciences & 0 \\
$0013-9165$ & Environment and Behavior & 10 \\
$0250-7161$ & Eure &
\end{tabular}




\begin{tabular}{clc} 
(continuação) & \multicolumn{1}{c}{ Periódicos } & \\
\hline ISSN & \multicolumn{1}{c}{ Críticas ou resenhas nos últimos dez números } \\
\hline $0267-3037$ & Housing Studies & 10 \\
$0300-7839$ & Human Ecology & 10 \\
$0143-1161$ & International Journal of Remote Sensing & 4 \\
$0192-5121$ & International Political Science Review & 0 \\
$0733-9488$ & Journal of Urban Planning and Development & 2 \\
$0264-8377$ & Land Use Policy & 1 \\
$1025-9112$ & Mine Water and the Environment & 2 \\
$1473-0952$ & Planning Theory & 9 \\
$0098-7921$ & Population and Development Review & 10 \\
$0199-0039$ & Population and Environment & 1 \\
$0032-4728$ & Population Studies & 9 \\
$0103-2070$ & Tempo Social & 6 \\
$0042-0980$ & Urban Studies & 8 \\
$0305-750 X$ & World Development & 0
\end{tabular}

\begin{tabular}{|c|c|c|}
\hline & Periódicos A2 & \\
\hline $1414-753 X$ & Ambiente e Sociedade & 5 \\
\hline 1808-5741 & Arquiteturarevista & 1 \\
\hline 0006-3444 & Biometrika & 0 \\
\hline $0261-3050$ & Bulletin of Latin American Research & 10 \\
\hline $0266-352 X$ & Computers and Geotechnics & 0 \\
\hline 0198-9715 & Computers, Environment and Urban Systems & 3 \\
\hline $0011-5258$ & Dados & 0 \\
\hline 0101-7330 & Educação \& Sociedade & 0 \\
\hline $0377-2217$ & European Journal of Operational Research & 7 \\
\hline 0016-7185 & Geoforum & 2 \\
\hline 1354-1013 & Global Change Biology & 4 \\
\hline 0104-7183 & Horizontes Antropológicos & 10 \\
\hline 0021-9320 & Journal of Biosocial Science & 7 \\
\hline 1443-2447 & Journal of Population Research & 6 \\
\hline 0104-9313 & Mana & 10 \\
\hline 0101-3300 & Novos Estudos Cebrap & 9 \\
\hline 0102-6909 & Revista Brasileira de Ciências Sociais & 10 \\
\hline 0102-3098 & Revista Bras. de Estudos de População & 10 \\
\hline $1517-4115$ & Revista Bras. de Estudos Urbanos e Regionais & 10 \\
\hline 0034-7329 & Revista Brasileira de Política Internacional & 3 \\
\hline $1315-9518$ & Revista de Ciencias Sociales & 3 \\
\hline 0103-2003 & Revista de Economia e Sociologia Rural & 0 \\
\hline 0104-4478 & Revista de Sociologia e Política & 0 \\
\hline 1138-9788 & Scripta Nova & 0 \\
\hline 0037-7686 & Social Compass & 0 \\
\hline 0102-6992 & Sociedade e Estado & 10 \\
\hline $1517-4522$ & Sociologias & 10 \\
\hline 1063-0732 & The Journal of Urban Technology & 4 \\
\hline $2175-3369$ & Urbe. Revista Brasileira de Gestão Urbana & 0 \\
\hline $1357-5317$ & Urban Design International & 6 \\
\hline \multirow[t]{2}{*}{$1750-712 X$} & Urban Design & 2 \\
\hline & & Taxa geral $=142 / 310(46 \%)$ \\
\hline
\end{tabular}

Fonte: Capes, Classificação de Periódicos. Disponível em: 〈http://qualis.capes.gov.br/webqualis/principal.seam〉. Acesso em: 07 de abril de 2014. Sites dos periódicos pesquisados.

Nota: No caso de periódicos com mais de uma resenha por número, pontuou-se apenas uma vez. 
Da leitura da Tabela 1, tem-se um percentual de publicação de resenhas no universo de periódicos analisados não superior a $50 \%$, valor significativo e acima dos pressupostos iniciais deste texto. Um olhar mais preciso, porém, confirma que a concentração de resenhas de modo sistemático ocorre em alguns periódicos e que muitos não publicam essa tipologia de texto. Além disso, estudos mais específicos poderiam discutir o quanto daquilo que se apresenta como resenha seria classificado, segundo o entendimento de Zuccala e Van Leeuwen (2011), na chamada resenha ou crítica do tipo 1 ou 2.0 percentual de $50 \%$ de números de periódicos com resenhas, de modo geral, se apresenta de maneira casual. A prática constante de resenha em todos os números, o que significaria uma política editorial deliberada para tal e certamente um esforço editorial adicional, é observada em apenas oito periódicos do total de 55 analisados. Para além dos percentuais, chama a atenção o fato de que raramente são encontrados pontos de vista e seus contrapontos, o que significaria uma clara valorização do debate.

Mais ainda, valeria identificar em quantos desses casos há o recurso da réplica, tal qual, por exemplo, fortemente observado na publicação Boston Review: criada em 1975, sua estrutura editorial é aquela de um artigo de referência seguido de uma quase dezena de outros artigos de rejeição ou de reiteração. Nós, da área de Planejamento Urbano e Regional / Demografia, temos material para esse debate? Fazemos técnica ou fazemos ciência? Há, conforme demonstrado por Shapin (2015), uma perigosa aproximação entre ciência e moral, a qual nos leva a uma confortável, porém pouco científica, entente cordiale? Uma convivência com a prática da Gestão Urbana, se justificada pela perspectiva social, seria benéfica para o seu desenvolvimento científico?

No material de pareceristas que antecede a publicação de um artigo, há muitas vezes um excelente material para observar esse debate. Entretanto, ele não sobrevive editorialmente ao processo de aprovação ou rejeição do artigo. No caso de se caminhar para aprovação, as sugestões do parecerista são assimiladas pelos autores e assim publicadas em forma de texto acordado; no caso de se decidir por rejeição, a análise dos pares igualmente não gera um debate passível de ser acessado por um público maior.

Para finalizar este texto que objetivou tão somente fomentar um pequeno debate sobre um grande debate, aquele cotidiano e intrínseco à ciência, ajudaria citar Wittgenstein (1968, p. 55), no prefácio de sua obra filosófica Tractatus. Neste caso, pode-se encontrar a prepotência autoral sobre um trabalho de grande esforço; porém, encontra-se também a defesa não do trabalho em si, mas sim daqueles que o seguem. No trabalho a ser continuado, à luz de novas perspectivas analíticas, repousa pois o valor maior da atividade científica.

Caso meu trabalho tenha valor, ele será duplo. Primeiramente, porque exprime pensamentos, valor que será tanto maior quanto melhor os pensamentos forem expressos. Nisto estou consciente de que estou muito aquém do possível, simplesmente porque minhas forças são poucas para cumprir a tarefa. Possam outros vir e fazer melhor.

No entanto, a verdade dos pensamentos comunicados aqui me parece intocável e definitiva, de modo que penso ter resolvido os problemas no que é essencial. Se não me engano, o segundo valor deste trabalho é mostrar quão pouco se conseguem quando se resolvem tais problemas. 


\section{Referências}

BOURDIEU, P. O campo científico. In: ORTIZ, R. (Org.). Pierre Bourdieu: sociologia. São Paulo: Ática, 1983.

EPSTEIN, B.; SILVERS, R. Editorial. The New Yorker Review of Books, v. 1, n. 1, Feb. 1963.

JONES, R. G.; FLEENOR, J.; SUMMERS, L. Book reviews and scientist-practitioner currency: a critical lever. The Industrial-Organizational Psychologist, v. 41, n. 4, Apr. 2004. Disponível em: 〈http://www.siop.org/tip/backissues/April\%2004/05jones.aspx〉 Acesso em: 04 dez. 2014.

MARTIN, B. Behind the scenes of scientific debating. Social Epistemology, v. 14, n. 2/3, p. 201209, 2000.

NICOLAISEN, J. Book review. In: HJØRLAND, B. Core concepts in Library and Information Science (LIS). 2005. Disponivel em: 〈http://www.iva.dk/bh/Core\%20Concepts\%20in\%20LIS/ articles\%20a/book_review.htm>. Acesso em: 22 fev. 2013.

PEDROSO, M. F. Sobre a estética das cidades. Camillo Sitte e a Der Stadtebau. Arquitextos, ano 5, 2005. Disponivel em: 〈http://www.vitruvius.com.br/revistas/read/arquitextos/05.058/488〉. Acesso em: 17 nov. 2014.

SANTOS, M. Técnica espaço tempo: globalização e meio técnico-científico informacional. 2. ed. São Paulo: Hucitec, 1994.

SHAPIN, S. The virtue of scientific thinking. Boston Review, January 20, 2015. Disponivel em: 〈http://www.bostonreview.net/steven-shapin-scientism-virtue〉. Acesso em: 22 jan. 2015.

SPINK, A.; ROBINS, D.; SCHAMBER, L. Use of scholarly book reviews: implications for electronic publishing and scholarly communication. Journal of the American Society for Information Science, v. 49, n. 4, p. 364-374, 1998.

WITTGENSTEIN, L. Tractatus logico-philosophieus. Tradução e apresentação de José Arthur Giannott. São Paulo: Companhia Editora Nacional e Editora da Universidade de São Paulo, 1968.

ZUCCALA, A.; VAN LEEUWEN, T. Book reviews in humanities research evaluations. Journal of the American Society for Information Science, v. 62, n. 10, p. 1979-1991, 2011.

\section{Sobre os autores}

Clovis Ultramari é arquiteto, professor do Programa de Pós-graduação em Gestão Urbana Mestrado e Doutorado / PPGTU da Pontifícia Universidade Católica do Paraná.

Manoela Massuchetto Jazar é arquiteta, professora em estágio docência do Curso de Arquitetura e Urbanismo da Pontifícia Universidade Católica do Paraná.

\section{Endereço para correspondência}

Pontifícia Universidade Católica do Paraná.

Programa de Pós-graduação em Gestão Urbana - PPGTU

Rua Imaculada Conceição, 1155

Caixa postal 16210

80215-901 - Curitiba-PR, Brasil

Recebido para publicação em 10/06/2015

Recomendado para publicação em 25/07/2015

Aceito para publicação em 25/08/2015 